\title{
NEW CARLSON-BELLMAN AND HARDY-LITTLEWOOD DYNAMIC INEQUALITIES
}

\author{
S. H. SAKer, C. TunÇ And R. R. Mahmoud
}

Abstract. In this paper, we will prove some new dynamic inequalities of Carlson and HardyLittlewood types on an arbitrary time scale $\mathbb{T}$. These inequalities as special cases contain the classical continuous and discrete Carlson-Bellman and Hardy-Littlewood type inequalities. The results will be proved by employing the time scales Hölder inequality, some algebraic inequalities and some basic lemmas designed and proved for this purpose.

Mathematics subject classification (2010): 26D10, 26D15, 43N05.

Keywords and phrases: Carlson-Bellman inequality, Hardy-Littlewood inequality, time scales.

\section{REFERENCES}

[1] R. P. Agarwal, D. O'Regan And S. H. SAKer, Hardy Type Inequalities on Time Scales, Springer, Cham, (2016).

[2] R. P. Agarwal, V. Otero-Espinar, K. Perera and D. R. Vivero, Basic properties of Sobolev's spaces on time scales, Advances in Difference Equations 2006 (2) (2006), 1-14.

[3] P. R. BEESACK, A simpler proof of two inequalities of Brodlie and Everitt, Proceedings of the Royal Society of Edinburgh: Section A Mathematics 84 (3-4) (1979), 259-261.

[4] R. Bellman, An integral inequality, Duke Math. J. 10 (1943), 547-550.

[5] M. Bohner And A. Peterson, Dynamic Equations on Time Scales: An Introduction with Applications, Birkhäuser, Boston, (2001).

[6] M. Bohner, A. Peterson, Advances in Dynamic Equations on Time Scales, Birkhäuser, Boston, 2003.

[7] K. W. Brodlie AND W. N. Everitt, On an inequality of Hardy and Littlewood, Proceedings of the Royal Society of Edinburgh, Section A. Mathematical and Physical Sciences 72 (3) (1975), 179-186.

[8] A. CABADA AND D. R. Vivero, Expression of the Lebesgue-integral on time scales as a usual Lebesgue integral; application to the calculus of-antiderivatives, Mathematical and Computer Modelling 43 (1) (2006), 194-207.

[9] A. CABADA AND D. R. Vivero, Criterions for absolute continuity on time scales, Journal of Difference Equations and Applications 11 (2005), 1013-1028.

[10] F. CARLson, Une inégalité, Ark. Mat. Astr. Fysik, 25B (1) (1934), 1-5.

[11] W. B. CATON, A class of inequalities, Duke Math. J. 6 (1940), 442-461.

[12] E. T. Copson, On two integral inequalities, Proceedings of the Royal Society of Edinburgh: Section A Mathematics 77 (3-4) (1977), 325-328.

[13] E. T. Copson, Two series inequalities, Proceedings of the Royal Society of Edinburgh: Section A Mathematics 83 (1-2) (1979), 109-114.

[14] R. M. Gabriel, An extension of an inequality due to Carlson, J. London Math. Soc. 12 (1937), $130-132$.

[15] G. H. Hardy And J. E. LitTlewood, Some integral inequalities connected with the calculus of variations, The Quarterly Journal of Mathematics 1 (1932), 241-252.

[16] G. H. Hardy, J. E. Littlewood and G. Polya, Inequalities, 2nd ed. Cambridge Univ. Press, 1934.

[17] G. H. HARDY, A note on two inequalities, J. London Math. Soc. 11 (1936), 167-170. 
[18] L. JiAnZHONG AND B. JiAng, Some extensions and improvements of discrete Carlson's inequality, J. Math. Res. Appl. 36 (1) (2016), 61-69.

[19] T. Kato, On an inequality of Hardy, Littlewood, and Polya, Advances in Mathematics 7 (3) (1971), 217-218.

[20] L. Larsson, L. Maligranda, J. PeČarić And L.-E. Persson, Multiplicative Inequalities of Carlson Type and Interpolation, World Scientific, New Jersey, London, Singapore, Beijing, Shanghai, Hong Kong, Taipei, and Chennai, (2006).

[21] V. I. LEVIN, Exact constants in inequalities of the Carlson type, Doklady Akad. Nauk SSSR (N. S.) 59 (1948), 635-638, (in Russian).

[22] M. J. Luo And R. K. Raina, A New extension of Carlson's inequality, Math. Ineq. Appl. 19 (2) (2016), 417-424.

[23] D. S. Mitrinović, J. E. PeČArić, And A. M. Fink, Inequalities Involving Functions and Their Integrals and Derivatives, Springer, Netherlands (1991).

[24] U. M. ÖZKAN AND H. YILDIRIM, Hardy-Knopp-type inequalities on time scales, Dynamic Systems and Applications 17 (3-4) (2008), 477-486.

[25] U. M. ÖZKAN AND H. YILDIRIM, Time scale Hardy-Knopp type integral inequalities, Communications in Mathematical Analysis 6 (1) (2009), 36-41.

[26] P. ŘEHÁK, Hardy inequality on time scales and its application to half-linear dynamic equations, J. Inequal. Appl. 5 (2005), 495-507.

[27] S. H. SAKER AND J. GRAEF, A New class of dynamic inequalities of Hardy's type on time scales, Dynamic Systems and Applications 23 (2014), 83-93.

[28] S. H. SAKer, D. O'Regan AND R. P. Agarwal, Dynamic inequalities of Hardy and Copson types on time scales, Analysis: International mathematical journal of analysis and its applications $\mathbf{3 4}$ (4) (2014), 391-402.

[29] S. H. Saker, D. O'Regan And R. P. Agarwal, Generalized Hardy, Copson, Leindler and Bennett inequalities on time scales, Math. Nachr. 287 (5-6) (2014), 687-698.

[30] S. H. Saker, D. O'Regan And R. P. Agarwal, Some dynamic inequalities of Hardy's type on time scales, Math. Ineq. Appl. 17 (3) (2014), 1183-1199.

[31] S. H. Saker, R. R. Mahmoud And A. Peterson, Weighted Hardy-type inequalities on time scales with applications, Mediterr. J. Math. 13 (2016), 585-606.

[32] H. WEYL, The theory of groups and quantum mechanics, Courier Corporation (1950). 